\title{
The impact of ATP-binding cassette transporters on metabolic diseases
}

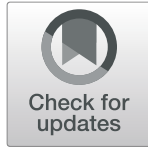

\author{
Zixiang Ye, Yifei Lu and Tao Wu (D)
}

\begin{abstract}
Currently, many people worldwide suffer from metabolic diseases caused by heredity and external factors, such as diet. One of the symptoms of metabolic diseases is abnormal lipid metabolism. ATP binding cassette (ABC) transporters are one of the largest transport protein superfamilies that exist in nearly all living organisms and are mainly located on lipid-processing cells. ABC transporters have been confirmed to be closely related to the pathogenesis of diseases such as metabolic diseases, cancer and Alzheimer's disease based on their transport abilities. Notably, the capability to transport lipids makes ABC transporters critical in metabolic diseases. In addition, gene polymorphism in $A B C$ transporters has been reported to be a risk factor for metabolic diseases, and it has been reported that relevant miRNAs have significant roles in regulating $A B C$ transporters. In this review, we integrate recent studies to examine the roles of $A B C$ transporters in metabolic diseases and aim to build a network with $A B C$ transporters as the core, linking their transport abilities with metabolic and other diseases.
\end{abstract}

Keywords: ATP binding cassette transporters, Metabolic diseases, Obesity, Atherosclerosis, T2DM, Tangier disease

\section{Introduction}

Currently, metabolic diseases are common in many countries. These diseases include a wide range of aliments, such as obesity, atherosclerosis (AS), stroke, type 2 diabetes mellitus (T2DM) and Tangier disease (TD). Individuals usually have several metabolic diseases at the same time. For example, people with obesity often also have AS or T2DM. In this case, it is promising and crucial to find a strategy that can effectively treat several metabolic diseases simultaneously.

Metabolic diseases can be caused by heredity and external factors such as diet. One of the roots of metabolic diseases is abnormal lipid metabolism. Recently, adenosine triphosphate (ATP)-binding cassette $(\mathrm{ABC})$ transporters have become a research hotspot in metabolic disease therapy due to its ability to regulate lipid metabolism.

\footnotetext{
* Correspondence: wutao001827@163.com

Center of Chinese Medical Therapy and Systems Biology, Institute of Interdisciplinary Integrative Medicine Research, Shanghai University of Traditional Chinese Medicine, Cailun Road 1200, Shanghai 201203, China
}

$\mathrm{ABC}$ transporters are one of the largest transport protein superfamilies [1]. The family of $A B C$ transporters has 49 members that are further divided into 7 subfamilies from $A$ to $G$ according to the sequence similarity and domain organization of the members $[2,3]$. ABC transporters are transmembrane proteins that are widely expressed in nearly all organisms and are located on cells and organelles. In humans, $A B C$ transporters are particularly expressed in cancer cells and lipidprocessing cells, such as macrophages [4-6].

$\mathrm{ABC}$ transporters can be classified into importers and exporters [7]. The transport mechanism of $A B C$ transporter is controlled by alternating the conformation of transmembrane domains (TMDs), through which the transporter switches between inward- and outwardfacing states [1]. Additionally, an increasing number of novel mechanisms have been explored. For example, Bi Y. et al. [8] discovered a processive $\mathrm{O}$ antigen translocation mechanism in gram-negative pathogens. Qian $\mathrm{H}$. et al. [9] identified lateral access for ABCA1-mediated lipid export. 
$\mathrm{ABC}$ transporters play a significant role in regulating the import and export of substances across plasma membranes. Driven by ATP, ABC transporters are able to carry a variety of substances across membranes such as small inorganic or organic molecules, sterol, metal ions, polypeptides and proteins $[10,11]$. One of the applications of $\mathrm{ABC}$ transporters is to regulate lipid metabolism. Specifically, ABC transporters participate in cholesterol uptake, biosynthesis and storage to maintain cholesterol homeostasis [5]. ABC transporters facilitate the formation of high-density lipoprotein-cholesterol (HDL-C). In addition, ABC transporters are negatively correlated with fasting blood glucose, total cholesterol (TC), low-density lipoprotein-cholesterol (LDL-C) and triacylglycerol levels [12]. Since abnormal lipid metabolism is associated with the pathogenesis of metabolic diseases, $A B C$ transporters participate in the inhibition of metabolic diseases, including AS, hypoalphalipoproteinemia (HA), coronary artery disease (CAD) and TD $[13,14]$.

$\mathrm{ABC}$ transporters have also received attention because of their effects on inducing multidrug resistance (MDR), especially in cancer conditions in which ABC transporters can reduce the efficacy of anticancer drugs [15]. In this case, $A B C$ transporters are also regarded as members of detoxification families, such as $\mathrm{P} 450$ monooxygenases, glutathione-S-transferases, and carboxylesterases [16]. Additionally, ABC transporters also link metabolic diseases with neoplasms. Metabolic diseases promote tumors. For example, it has been reported that metabolic syndrome (MetS) is an obvious pathogenic factor for epithelial ovarian cancer [17]. The loss of cellular cholesterol homeostasis has been found frequently in prostate cancer cells [18]. Additionally, obesity has been confirmed to support the development and progression of melanoma and controlling body weight is effective for suppressing melanoma [19, 20]. Apart from reducing the expression of tumor markers and the precision of radiotherapy, excess adipose tissue is able to alter the pharmacokinetics of chemotherapeutic drugs. Obesity-associated adipokines, leptin and resistin, can upregulate ABCB1 (P-glycoprotein, $\mathrm{P}$-gp). ABCB1 is part of the MDR family and facilitates the efflux of chemotherapeutic drugs from cancer cells. The efflux of drugs causes drug accumulation in plasma and consequently induces toxicity to organs [21]. Moreover, AS is correlated with cancer. It has been reported that up to $30 \%$ of cancer patient deaths are related to cardiovascular diseases [22]. Lectin-like oxidized low-density lipoprotein receptor-1 (LOX-1) is activated in AS. LOX-1 is a marker of AS and is induced by oxidized low-density lipoproteins (oxLDL). Since ABC transporters can decrease oxLDL levels, $A B C$ transporters are likely to be impaired in AS. LOX-1 is capable of inducing adhesion molecules, proinflammatory signaling pathways and proangiogenic proteins such as NF- $\mathrm{B}$ [23]. NF- $\mathrm{kB}$ can facilitate the production of reactive oxygen species (ROS), which then leads to lipid peroxidation and DNA damage that ultimately stimulate the progression of AS and cancer.

Overall, ABC transporters have a close relationship with metabolic diseases. In addition, their ability to cause MDR and facilitate metabolic diseases associated with cancer make $\mathrm{ABC}$ transporters a focus in cancer treatment. In this manner, an overall understanding of $\mathrm{ABC}$ transporters is key to treating cancer patients with metabolic diseases. In this review, we elucidated the structure and transport mechanism of $\mathrm{ABC}$ transporters. There are several ABC transporters that have a relationship with metabolic diseases. Additionally, we introduced a treatment strategy focusing on $\mathrm{ABC}$ transporters, including related microRNAs (miRNAs) and available drugs. The present review aims to make a contribution to building a network with ABC transporters as the core, linking transport functions with metabolic and other diseases.

\section{Structure of $A B C$ transporters}

Typically, ABC transporters consist of a combination of two TMDs and two cytoplasmic nucleotide-binding domains (NBDs). TMDs are variable in sequence and mechanism while NBDs are highly conserved and have characteristic amino acid motifs such as Walker A and Walker B [3, 24, 25]. Walker A and Walker B are key identifiers of $A B C$ proteins [6]. TMDs and NBDs interact with each other closely to transport substances and hydrolyze ATP, respectively [24].

The numbers of TMDs and NBDs differ in different organisms. In prokaryotes, $\mathrm{ABC}$ transporters have all four of these domains, while in eukaryotes, the number of domains is diverse. Specifically, some proteins have all four domains, which are organized as a single polypeptide named full-transporter (FT). Other proteins have a single TMD and NBD and are called half-transporters (HTs), which need to homo or heterodimerize to be functional. Furthermore, there is an ABC2 structure with two NBDs and a single structure with only one TMD or NBD $[3,6,11]$.

\section{The Transmembrane domain: a porter of substances}

Two TMDs are intertwined with 4-6 transmembrane $\alpha$ helices to form a cavity that is involved in substrate binding, recognition, transportation and making contacts with NBDs $[4,16,24]$. TMDs need to undergo conformational changes, and the degree of opening is diverse during transportation but has no close relationship with the size of the substance [1]. It has been reported that the location of pathogenic variations likely causes a shift 
in the pivot-like residue movement in TMDs, which weakens ATP binding and the interactions on the membrane surface [26]. In addition, several $A B C$ transporters including ABCA1 and ABCC6 have an additional TMD (TMD0) at the amino-terminal extension region of the protein [4, 27]. TMD0 is approximately 250 amino acids long and is highly hydrophobic, with five transmembrane helices. This extra domain is important for normal functions and its absence can make the $A B C$ protein unstable [24].

\section{The nucleotide-binding domain: the engine of $A B C$ transporters}

NBDs bind and hydrolyze ATP to supply energy for TMD conformational changes. This action is initiated by the presence of substrates [24, 28]. ATP is bound in the nucleotide binding site that is formed by an end-to-end connection of two NBDs [4].

\section{The substrate-binding protein: the initiator of $A B C$ transporters}

The substance is delivered by substrate-binding proteins (SBPs) that are fused to the TMDs to form one, two, or four substrate binding sites. SBPs consist of $\mathrm{N}$ - and Cterminal lobes connected by a hinge region. The lobes rotate facing each other to form a closed structure when SBPs bind a substrate. This form can productively trigger ATPase activity to initiate ABC transporters [4].

\section{$A B C$ importer I and II}

$\mathrm{ABC}$ importers can be further divided into importer I and II based on the numbers of transmembrane helices and the chemical nature of their substrates [10]. TMDs of type II importers including vitamin B12 and molybdate II transporters have more modest conformational changes but no specific substrate binding sites [4]. NBDs of type I importers typically have low ATPase activity and only hydrolyze ATP with high efficiency in the presence of a substrate-loaded SBP. In contrast, type II importers typically have high ATPase activity that is independent of substrate availability. Moreover, SBPs of type I importers undergo more significant conformational changes when binding to substrates than type II importers. Notably, many type I importers, such as maltose transporters, contain $\mathrm{C}$-terminal regulatory domains that prevent ATP hydrolysis when the importer is bound to substrates. Interestingly, these two types of import systems can exist in a single transporter, such as the ribose transporter [7].

\section{Mechanisms of $A B C$ transporters: an opening and closing transport gear}

The transport function of $\mathrm{ABC}$ transporters is a circular process, as shown in Fig. 1. Taking the importer as an example, at the beginning, the transporter is in the inward-facing state. When periplasmic SBPs deliver a substrate to the TMDs, the NBDs bind and hydrolyze ATP, accompanied by a closing motion with sliding and rotation. This twisting motion is further propagated to the TMDs via the intracellular helices IH1 and IH2. In this manner, the TMDs are switched to the outwardfacing state. Then, the substrate is delivered to the substrate binding site in the TMDs. The subsequent hydrolysis of ATP leads to substrate uptake across the lipid bilayer and phosphate release makes the transporter revert to the inward-facing state [29-31]. During this process, both ATP binding and SBP binding participate in maintaining the outward-facing state of the transporter [32].

\section{ABC transporter members}

Although all of the ABC transporters are capable of transmembrane transport, their substrates are diverse. For example, ABCA1, ABCA2, ABCA7, ABCA8 and ABCG1 transport lipids, while $\mathrm{ABCC} 1$ and $\mathrm{ABCG} 2$ transport xenobiotics, especially anticancer drugs. Regarding metabolic diseases, ABCA1 has attracted the most attention compared with that of the other $\mathrm{ABC}$ transporters. Moreover, there are several signaling pathways that can modulate the expression of $\mathrm{ABC}$ transporters or can be regulated by $\mathrm{ABC}$ transporters (shown in Fig. 2). Therefore, a deep understanding of the relationship between $\mathrm{ABC}$ transporters and related signaling pathways is important for treating relevant diseases. Here, we summarize a number of $\mathrm{ABC}$ transporters and their respective biological significance.

ABCA 1: the hottest research topic in metabolic disease ABCA1 is widely expressed, especially in the liver, gastrointestinal tract, adipose tissue and macrophages [33]. This protein is expressed on the plasma membrane [34].

ABCA1 participates in the initial step of reverse cholesterol transportation (RCT) by regulating the movement of excess cholesterol and phospholipids from peripheral tissues to the liver. ABCA1 is able to form modest nascent HDL particles by binding with lipidpoor or lipid-free apolipoprotein (apo) A-I and apoE [35, 36]. ABCA1-knockout mouse models have demonstrated that ABCA1 is critical in mediating lipid efflux, and HDL formation and homeostasis [37]. ABCA1 generally cooperates with ABCG1 and scavenger receptor-BI (SR$\mathrm{BI})$ to assemble HDL [33]. The contribution of hepatic and intestinal ABCA1 to the plasma HDL pool is 70$80 \%$ and $15-20 \%$, respectively [38]. In cells, ABCA1 mediates lipid transport between the Golgi and cell membrane [39]. 


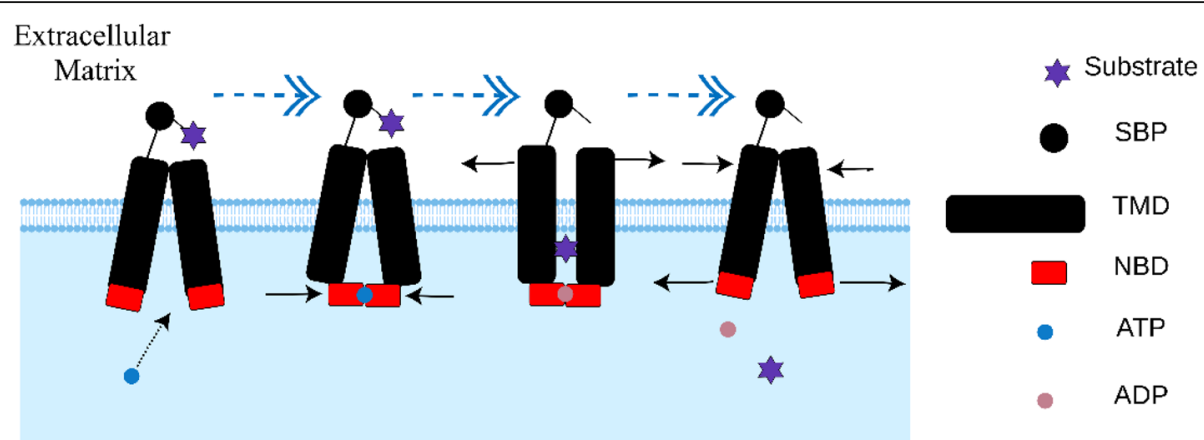

Fig. 1 Mechanism of ABC importers. SBP binding to a substrate leads to NBD binding to ATP and a large-scale closing motion. The motion makes TMDs switch to the outward-facing state. The subsequent hydrolysis of ATP leads to the substrate crossing the lipid bilayer, and phosphate release initiates the return of the transporter to its initial state. Abbreviations: ABC, adenosine triphosphate-binding cassette; SBP, substrate-binding protein; NBD, nucleotide-binding domain; TMD, transmembrane domain

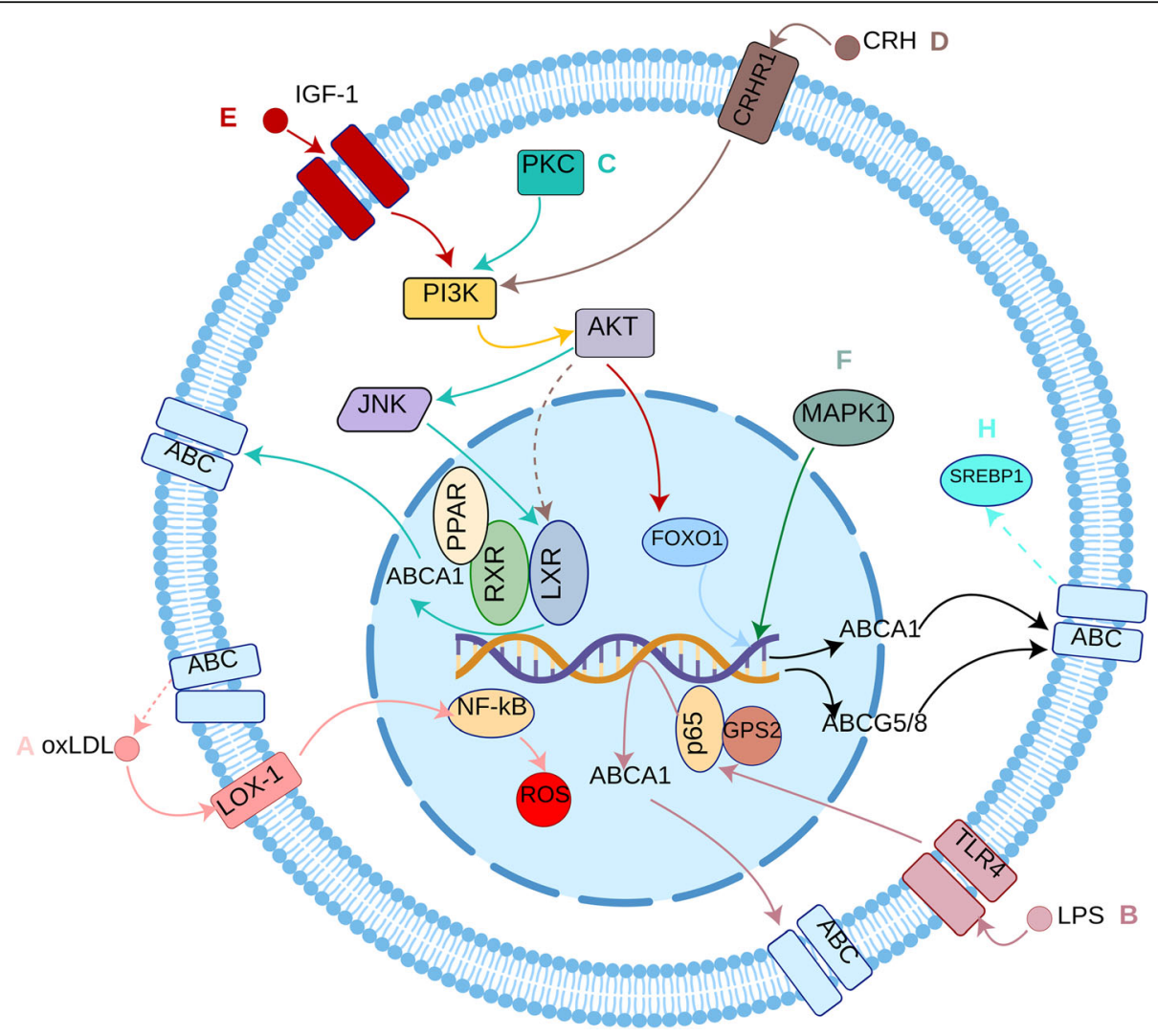

Fig. $2 A B C$ transporter-related signaling pathways. A: Inhibition of $A B C$ transporters can lead to an increase in oxLDL (shown by dotted line). oxLDL can cause inflammation through the LOX-1/NF-KB pathway to induce ROS production. B: LPS can induce ABCA1 via the TLR4/GPS2/NF-KB pathway to upregulate the gene expression of ABCA1. C: The PKC/PI3-K/Akt/JNK/LXR/RXR pathway is positively correlated with the expression of ABCA1. D: CRH can inhibit the activation of LXR (shown by dotted line) via the CRHR1/PI3-K/Akt pathway. E: IGF-1 can induce the PI3-K/Akt/ FOXO1 pathway to activate FOXO1 which can facilitate the transcription of ABCA1 and ABCG5/8. F: MAPK1 can induce the expression of ABCA1. $\mathrm{H}$ : Expression of ABC transporters can inhibit the activation of SREBP (shown by dotted line), which can reduce lipogenesis. Abbreviation: ABC: Adenosine triphosphate-binding cassette; oxLDL: Oxidized low-density lipoproteins; LOX-1: Lectin-like oxidized low-density lipoprotein receptor-1; ROS: Reactive oxygen species; LPS: Lipopolysaccharides; TLR4: Toll-like receptor 4; GPS2: G protein pathway suppressor 2; PKC: Protein kinase C; PI3-K: Phosphatidylinositol 3-kinase; Akt: Protein kinase B; JNK: C-Jun N-terminal kinases; LXR: Liver X receptor; RXR: Retinoid-X-receptor; CRH: Corticotropin-releasing hormone; CRHR1: Corticotropin-releasing hormone receptor 1; IGF-1: Insulin-like growth factor 1; FOXO1: Forkhead box protein O1; MAPK1: Mitogen-activated protein kinase 1; SREBP: Sterol regulatory element binding protein; PPAR: peroxisome proliferator-activated receptor 
ABCA1 also plays an important role in responding to abnormal cholesterol metabolism-related conditions, such as inflammation. Cholesterol efflux is relevant to inflammation at the transcription level [40]. ABCA1 has been reported to exert anti-inflammatory effects by inhibiting the production of some inflammatory cytokines in macrophages [13]. Moreover, ABCA1-mediated cholesterol efflux can inhibit lipopolysaccharide (LPS)-induced inflammatory signaling [41].

The ABCA1 gene is located on chromosome 9q31.1 [42]. Several gene polymorphisms of ABCA1 have been studied [43]. For example, the R219K (rs2230806) polymorphism is located at the $\mathrm{N}$-terminal extracellular loop of the ABCA1 protein. I883M (rs4149313) is correlated with a marked decrease in HDL-C and cholesterol efflux [36, 39]. Mohammad M.B. et al. [13] reported that the increased risk of HA, decreased HDL-C and increased TG, interleukin 6 (IL-6) and C-reactive protein (CRP) are correlated with the ABCA1-565 $\mathrm{C} / \mathrm{T}$ gene polymorphism.

ABCA1 transcription can be regulated by obligate heterodimers of liver $\mathrm{X}$ receptors (LXRs) and retinoid $\mathrm{X}$ receptors (RXRs), bacterial endotoxins such as LPS and peroxisome proliferator-activated receptors (PPARs) [40, 44, 45]. LXR is a transcription factor for ABCA1 [46]. Unsaturated fatty acids can suppress ABCA1 expression post transcriptionally via $L X R$ and can facilitate ABCA1 degradation. LPS activates ABCA1 by inducing the cooperation of NF- $\mathrm{kB}$ subunit p65 and the transcriptional coregulator G protein pathway suppressor 2 (GPS2) [40]. In addition, endocytosis is able to regulate ABCA1 expression, which is mediated by the ADP-ribosylation factor 6 (ARF6)-dependent pathway [34].

\section{ABCA2: a potential solution to Alzheimer's disease}

The ABCA2 protein has the highest homology with ABCA1 due to the duplication of ancestral genes during evolution. It is naturally expressed in brain tissue and blood cells including macrophages, monocytes and blood stem cells. Furthermore, ABCA2 is mainly located intracellularly on late endosomes, lysosomes, the trans Golgi and the endoplasmic reticulum (ER). ABCA2 is able to maintain the homeostasis of sterols, sphingolipids and cholesterol in macrophages and neurons [47]. ABCA2 transporters have been reported to be related to diseases such as cholesterolemia, cardiovascular disease, Alzheimer's disease and cancer.

\section{ABCA3: a possible target in respiratory diseases}

Mutations in the ABCA3 gene have been confirmed to result in fatal surfactant deficiency, particularly respiratory distress syndrome (RDS) in babies and childhood interstitial lung disease $[48,49]$.
ABCA7: a bridge connecting cholesterol metabolism with the immune system

Exogenous ABCA7 mediates the biogenesis of HDL from cellular lipids and helical apo. Endogenous ABCA7 has a relationship with phagocytosis, which is controlled by sterol regulatory element binding protein 2 (SREBP2). Thus, ABCA7 is assumed to be a key molecule that connects cholesterol homeostasis and the body defense system [50]. The absence of ABCA7 has a significant impact on natural killer $\mathrm{T}$ (NKT) cell development and activation. In addition, overactive NKT cells have been implicated in the development of AS, autoimmunity, rheumatoid arthritis, and several forms of allergies [51]. Furthermore, ABCA7 has been considered a promising target in Alzheimer's disease [52].

\section{ABCA8}

It has been reported that $\mathrm{ABCA} 8$ acts as a sinusoidal efflux transporter for cholesterol and taurocholate in the liver [53].

\section{ABCB6: a supporter of cytochrome P450}

ABCB6 deficiency suppresses cytochrome P450 (CYP450) expression in mouse and human hepatocytes. Ablation of ABCB6 reprograms the hepatic metabolic profile to negatively regulate hepatic CYP expression, possibly as a homeostatic response to promote survival. CYP450s constitute a superfamily of monooxygenases that play key roles in the metabolism of endogenous and exogenous compounds [54].

\section{$A B C C 1$ : one of the initiators of multidrug resistance}

$\mathrm{ABCC} 1$, also known as multidrug resistance protein 1 (MRP1), prevents xenobiotics such as drugs from entering tissues. In addition, $\mathrm{ABCC} 1$ transports physiological substances such as folic acid, bilirubin, vitamin B12, and many glutathione and glucuronide conjugates. ABCC1 also secretes a variety of mediators that regulate redox homeostasis, inflammation, and hormone secretion. Overexpression of ABCC1 has been found in a variety of cancers such as lung cancer, leukemia and breast cancer [55].

\section{ABCG1: a porter of intracellular cholesterol}

ABCG1 mainly accumulates in cells [56]. ABCG1 is expressed in the ER, trans-Golgi network (TGN) and endosomal recycling compartment (ERC) [5].

ABCG1 deficiency leads to profound intracellular cholesterol accumulation in macrophages and hepatocytes $[57,58]$. Furthermore, ABCG1 is able to sense and manage membrane trafficking [5]. ABCG1 is short-lived, and both proteasomal and lysosomal inhibitors can decrease its degradation [5]. It has been reported that ABCG1 deficiency is associated with mild glucocorticoid 
insufficiency in mice because cholesterol is the sole precursor for glucocorticoid synthesis [59].

\section{ABCG2: the initiator of multidrug resistance in breast Cancer and the blood-brain barrier}

ABCG2, also known as breast cancer resistance protein (BCRP), is abundantly expressed in the small intestine and liver [60]. ABCG2 is capable of affecting stem cell biology and controlling the excretion of various drugs, phase II metabolites, and endogenous substrates such as uric acid, toxic xenobiotics, and heme [15]. ABCG2 can excrete protoporphyrin (PP) from hepatocytes into the bile canaliculi. Thus, the formation of erythropoietic protoporphyria (EPP) may be a consequence of decreased ABCG2 expression, which ultimately leads to severe liver damage [61]. ABCG2 on the blood-brain barrier (BBB) also prevents therapeutic molecules from entering the brain parenchyma. Bakhsheshian J. et al. [62] established a relatively simple protocol for imaging ABCG2 at the BBB by determining the bioluminescence image (BLI) of luciferase because ABCG2 can specifically transport D-luciferin on the apical membrane of capillary endothelial cells in the BBB.

\section{microRNAs and $A B C$ transporters: a promising strategy}

Since people often develop multiple metabolic aliments simultaneously, it is desirable to have a therapy that can target several metabolic diseases at the same time. Considering that one of the roots of metabolic disease is abnormal $\mathrm{ABC}$ transporter-related lipid metabolism, microRNA (miRNA) therapy has been identified as a promising strategy to radically treat metabolic diseases. MiRNAs are able to regulate mRNA transcription and can affect multiple genes within a signaling pathway or target several pathways at the same time [63]. Thus, if the miRNAs are carefully chosen, it is likely that related mRNAs in disease conditions can be specifically altered. In other words, the miRNA strategy can make treatment more targeted and have fewer side effects and toxicity than conventional therapy. In addition, the miRNA strategy can also treat hereditary metabolic diseases. The small size of miRNAs also overcomes the low effect and specific delivery of traditional gene therapy which uses large DNA plasmids or viral vectors encoding a protein [64]. Recently, miRNAs have been potential candidates as therapeutics (miRNA mimics) or targets of therapeutics (anti-miRs) [65]. An increasing number of miRNA therapies have been developed or applied to treat metabolic diseases and cancers [66]. Thus, it is important to identify $\mathrm{ABC}$ transport-related miRNAs and understand their effects on signaling pathways and the expression of $\mathrm{ABC}$ proteins. In this section, we described several miRNAs and their effects on ABC transporters (Table 1.)
miR-19b

miR-19b promotes lipid metabolism abnormalities by binding to the 3 '-UTR of ABCA1 transporters. It has been reported that glucagon-like peptide-1 (GLP-1) can upregulate the expression of ABCA1 by suppressing miR-19b [74].

\section{miR-20}

miR20 can regulate ABCA1 at the posttranscriptional level and consequently influence cholesterol efflux and AS. miR-20a/b can suppress ABCA1 by directly binding to ABCA1 mRNA with low binding free energy. It has been found that miR-20a/b can decrease cholesterol efflux and increase cholesterol levels in THP-1 cells and RAW 264.7 macrophage-derived foam cells. Therefore, miR-20 inhibition constitutes a new strategy for ABCA1-based treatment of AS [68].

\section{miR-23a-5p}

ABCA1 and ABCG1 are novel targets of miR-23a-5p. Yang $S$ et al. [69] reported that the level of miR-23a-5p was elevated in plasma and macrophages in AS. In acute ischemic stroke (AIS) patients, carotid atherosclerotic plaque progression could be worsened by the presence of miR-23a-5p. miR-23a-5p antagonist therapy significantly reduced foam cell formation and AS progression and promoted plaque stability.

\section{miR-28}

miR-28 can induce ABCA1 expression in patients with unstable angina by inhibiting mitogen-activated protein kinase 1 (MAPK1) [70]. The function of miR-28 has a close relationship with its host gene, LIM domain lipoma-preferred partner (LPP), which facilitates smooth muscle cell migration in arterial injury and AS.

\section{miR-33}

miR-33 has been reported to downregulate ABCA1 and ABCG1 expression [71]. It has been identified as an indirect regulator of innate immunity that mediates bidirectional crosstalk between lipid homeostasis and inflammation by directly targeting Toll-like receptor (TLR) pathway members and cytokines. miR-33 augments macrophage lipid rafts and enhances proinflammatory cytokine induction and NF- $\mathrm{BB}$ activation by LPS. This effect occurs through an ABCA1- and ABCG1dependent mechanism and is reversible by interventions with raft cholesterol and ABC transporter-inducing LXR agonists [72].

\section{miR-101}

miR-101 can repress ABCA1 expression to facilitate intracellular cholesterol retention under inflammatory conditions. Zhang $\mathrm{N}$ et al. [73] suggested that miR-101 
Table 1 Reported miRNA and their target $A B C$ transporter

\begin{tabular}{lllll}
\hline miRNA & Targeted ABC transporter & Effect & Consequence & Reference \\
\hline miR-19b & \multicolumn{1}{c}{ ABCA1 } & $\downarrow$ & Aggravating AS & Lv YC et al., 2015 [67] \\
miR-20 & ABCA1 & $\downarrow$ & Aggravating AS & Liang B et al., 2017 [68] \\
miR-23a-5p & ABCA1\&ABCG1 & $\downarrow$ & Aggravating AS\&AIS & Yang S et al., 2018 [69] \\
miR-28 & ABCA1 & $\uparrow$ & Attenuating AS & Liu J et al., 2016 [70] \\
miR-33 & ABCA1\&ABCG1 & $\downarrow$ & Aggravating Inflammation & Niesor EJ et al., 2015 [71] \\
& & & Aggravating NAFLD\&AS & Lai Let al., 2016 [72] \\
miR-101 & ABCA1 & $\downarrow$ & Zhang N et al., 2015 [73]
\end{tabular}

Abbreviations: miR microRNA; $A B C$ adenosine triphosphate-binding cassette; $A S$ atherosclerosis; $A / S$ acute ischemic stroke; NAFLD non-alcoholic fatty liver disease

promoted the development of nonalcoholic fatty liver disease (NAFLD) and vascular AS.

\section{ABC transporters and metabolic diseases: abnormal lipid metabolism}

Since $A B C$ transporters are responsible for mediating lipid homeostasis, they are closely related to metabolic diseases. Impaired $A B C$ transporters can lead to excess free cholesterol which is toxic to adipocytes and macrophages. Toxicity can promote the unfolded protein response (UPR) and induce apoptosis via the ER [47]. Recently, the role of ABCA1 and ABCG1 in metabolic diseases has been the most studied (Fig. 3).

\section{Metabolic syndrome}

MetS includes a variety of metabolic disorders and is characterized by increased waist circumference, hyperglycemia, hypertriglyceridemia, low HDL-C levels and hypertension. Chen WM et al. [12] suggested that MetS could be induced by impaired ABCA1 and that hyperglycemia further suppressed ABCA1 expression in macrophages via posttranscriptional regulation. At the same time, people with MetS were at high risk of developing T2DM and cardiovascular disease.

\section{Obesity}

Obesity is a common metabolic disease. In obese adults, adipose tissues usually contain over $50 \%$ of the TC in the body [39]. Obesity is associated with reduced expression of ABCA1 in visceral adipose tissues [38]. Adipocyte ABCA1 is a key regulator of adipocyte lipogenesis and lipid accretion, likely due to increased cholesterol on adipose tissue membranes. ABCA1 can suppress the activity of the lipogenic transcription factors PPAR $\gamma$ and SREBP1 [75]. It has been confirmed in mouse models that a lack of adipocyte-specific ABCA1 leads to obesity. In addition, these mice without adipocyte-specific ABCA1 also showed decreased levels of the most active

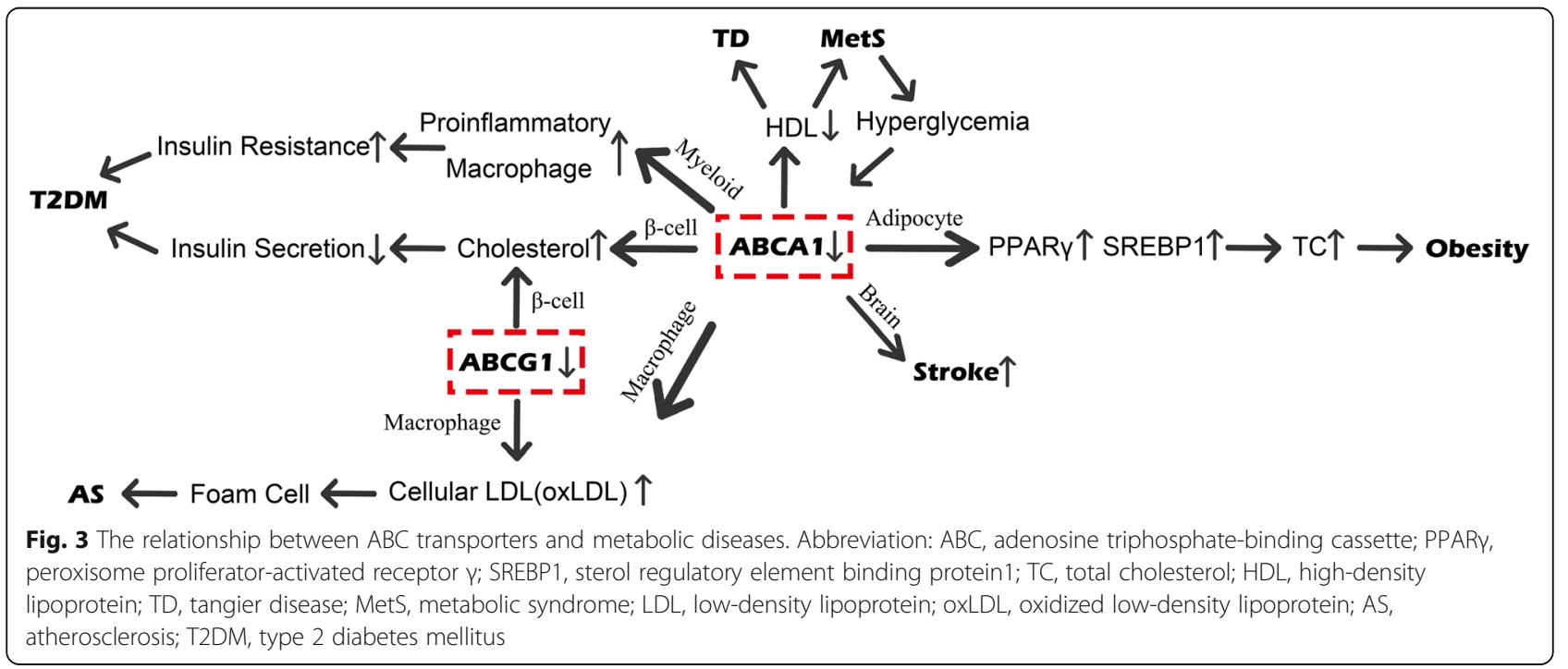


form of adiponectin and high-molecular-weight adiponectin [38]. Furthermore, GPS2 has been found to be downregulated in obese and T2DM subjects, providing additional evidence for the repression of ABCA1 in obesity and T2DM [40]. There are two single nucleotide polymorphisms (SNPs) of the ABCA1 gene, R219K and I883M, that have been found to have a close relationship with susceptibility to obesity. The SNP R219K increases susceptibility and phenotype severity, and of the SNP I883M plays a protective role [39].

\section{Atherosclerosis}

The macrophage-mediated cholesterol uptake and metabolism is associated with the initiation and progression of AS in focal areas of the arterial subendothelial space [40]. The formation of lipid-laden macrophages, also known as foam cells, is the initial step of AS. Foam cell development is inhibited by macrophage expression of $A B C A 1$ and $A B C G 1$ [76]. Impaired macrophage ABCA1 and ABCG1 expression results in reduced cholesterol efflux and excess uptake of modified LDL, especially oxLDL, which further generates foam cells $[46,58]$. The ABCA1 C69T polymorphism has been confirmed to be associated with increased AS risk [77]. Although RCT is a major mechanism by which HDL protects against AS, the atheroprotective effect of ABCA1 is not fully dependent on RCT $[46,78]$. Interestingly, myeloid cell ABCA1 increases hepatic very-low-density lipoprotein (VLDL) TG secretion and plasma VLDL/LDL ratios, which reduces the atheroprotective effect and leads to a minimal increase in AS [79]. It has been reported that ABCG1 plays a role in promoting the progression of advanced atherosclerotic lesions by inducing the necrotic core of the atherosclerotic plaque [57]. Lipid-rich plaques can become unstable, leading to thrombosis, cardiac arrest and death. Davis W et al. [47] confirmed that ABCA2 can also reduce unstable lipid-rich plaques in macrophages. Cholesterol-induced toxicity can cause intracellular lipid-rich plaques, and ABCA2 can eliminate these plaques by modulating cholesterol trafficking from the late endosome/ lysosomal membrane compartment (LE/LY) to the ER in cells.

Several factors can affect the expression of ABCA1 and ABCG1. Sortilin is closely associated with hyperlipidemia and the risk of AS. Macrophage sortilin expression is upregulated by oxLDL in both concentrationand time-dependent manners. Sortilin can bind with ABCA1 and suppress macrophage ABCA1 expression by enhancing lysosomal degradation of ABCA1 [80]. Additionally, AS can also be caused by psychological stress factors such as corticotropin-releasing hormone (CRH). $\mathrm{CRH}$ can suppress $\mathrm{ABCA1}$ and promote stress-related AS by activating CRH receptor 1 (CRHR1)-induced phosphorylation of protein kinase $\mathrm{B}$ (Akt).
Phosphorylation of Akt is also induced by insulin and adiponectin to repress ABCA1 expression in human monocyte-derived macrophages. In addition, the phosphatidylinositol 3-kinase (PI3-K)/Akt signaling pathway suppresses the expression of both LXR and ABCA1 and can be activated by the cooperation of $\mathrm{CRH}$ and pregnancy-associated plasma protein-A (PAPP-A) [46].

AS is likely to cause CAD. CAD commonly manifests as reduced HDL-C levels, which are crucial factors in the morbidity and mortality of CAD patients [36]. The ABCA1 R219K polymorphism $\mathrm{K}$ allele shows a protective effect by increasing HDL-C levels, and its function has been reported to be independent of plasma lipid levels $[36,81]$. The ABCA1 C-565 $\mathrm{T}$ promoter polymorphism is also a significant risk factor for the development and severity of CAD [82].

\section{Stroke}

The ABCA1 gene is a key target of the transcription factor LXR. LXR activation has anti-inflammatory and neuroprotective effects in animal ischemic stroke models. Brain ABCA1 deficiency increases BBB leakage, white matter (WM)/axonal damage and functional deficits after stroke. Concomitant reduction of insulin-like growth factor 1 and upregulation of matrix metalloproteinase- 9 may contribute to brain ABCA1 deficiency-induced $\mathrm{BBB}$ and $\mathrm{WM} / \mathrm{axonal}$ damage in the ischemic brain [83]. In addition, $\mathrm{Li} \mathrm{Q}$ et al. [58] reported that ABCG1 polymorphisms could attenuate ischemic stroke in a hypertriglyceridemic population with atherothrombotic stroke.

\section{Type 2 diabetes mellitus}

T2DM is characterized by impaired insulin resistance, insulin secretion, and dysregulation of lipid and protein metabolism [42]. Impaired ABCA1 functions in pancreatic $\beta$-cells can cause the accumulation of cholesterol and a decrease in HDL-C, which leads to a reduction in insulin secretion and consequently reduces glucose tolerance, ultimately causing T2DM [84].

It has been reported that myeloid-specific ABCA1 gene deletion results in proinflammatory macrophages. Cytokines produced by macrophages in adipose tissue contribute to the development of insulin resistance [75]. However, there is a debate regarding whether the ABCA1 gene polymorphism is a genetic risk factor for T2DM $[35,85]$. Insulin-like growth factor 1 (IGF-1) can mediate the stimulation of ABCA1 gene expression by inducing the PI3-K/Akt/Forkhead box protein O1 (FoxO1) pathway [86]. In addition, the expression of ABCA1 and miR-27a can be increased and decreased, respectively, via GLP-1. GLP-1 has been revealed to protect and improve pancreatic $\beta$-cell function against 
lipotoxicity which is considered one of the main causes of deterioration in $\beta$-cell function [87].

ABCG1 is essential for forming insulin granules, and ABCG1 deficiency inhibits insulin secretion by pancreatic $\beta$-cells. ABCG1, in addition to ABCA1 and oxysterol binding protein (OSBP), supports insulin granule formation [5]. Diabetes is usually accompanied by diabetic cardiovascular complications such as neointima formation because of endothelial progenitor cell (EPC) dysfunction. This dysfunction can be ameliorated by ABCG1 by promoting migration, tube formation and differentiation, and subsequent re-endothelialization of EPCs [88].

\section{Tangier disease}

TD is characterized by nearly exhausted plasma HDL, increased TG levels, sterol deposition in tissue macrophages and increased susceptibility to coronary heart disease (CHD) $[37,89]$. TD is caused by mutations in the ABCA1 gene. ABCA1-deficient HLCs fail to mediate lipid efflux or nascent HDL formation but have elevated TG secretion. In addition, it has been reported that TD patients have increased angiopoietin related protein 3 (ANGPTL3), which is an inhibitor of lipoprotein lipase (LPL), and influences HDL and TG metabolism [37]. TD patients also have hyporeactivity of blood platelets [16]. The absence of ABCA1 and low HDL levels reduce platelet reactivity by decreasing positive feedback loops, particularly thromboxane A2 (TXA2) production through a hematopoietic ABCA1-independent mechanism [90].

\section{Drug that mediate $A B C$ transporters: $A B C$ transporter antagonists and agonists}

At present, an increasing number of drugs have been developed or are in development to treat $\mathrm{ABC}$ transporterrelated metabolic diseases and cancer..

$\mathrm{ABC}$ transporters can lead to chemoresistance by facilitating drug efflux [91]. For example, overexpression of ABCB1 in human ovarian and breast cancer greatly suppresses the efficacy of chemotherapeutic drugs such as paclitaxel, vinca alkaloids and doxorubicin. Therefore, $\mathrm{ABC}$ transporter inhibitors have been considered an efficient way to restore tumor sensitivity to anticancer drugs. Recently, several man-made or natural ABC antagonists have been developed to treat cancer. Imatinib is a synthetic chemotherapeutic drug that is able to treat leukemia via down-regulating the mRNA and protein of $\mathrm{ABCB} 1$. In addition, it has been reported that natural products, including polyphenols, flavonoids and alkaloids, can reverse $\mathrm{ABC}$ transporter-related MDR [92]. For example, tetrandrine, a bisbenzylisoquinoline alkaloid isolated from Stephania tetrandra S. Moor, inhibits ABCC1 to reverse MDR in esophageal cancer [93].

Apart from treating cancer, $\mathrm{ABC}$ transporter antagonists and agonists are also utilized to alleviate metabolic diseases. These are ideal treatments for curing metabolic diseases because they can treat several metabolic diseases simultaneously. Here, we described several drugs and their mechanisms and effects on $A B C$ proteins (Table 2). In summary, many of these drugs mediate

Table 2 Drugs to mediate $A B C$ transporters

\begin{tabular}{|c|c|c|c|c|c|}
\hline Drug & Target & Effect & Mechanism & Source & Reference \\
\hline Statins & $A B C A 1$ & Reduce & $\begin{array}{l}\downarrow P \mid 3-K / A k t / F O X O 1 \\
\& \downarrow T L R 4 / N F-k B\end{array}$ & Synthetic & $\begin{array}{l}\text { Chen WM } \\
\text { et al., } 2016 \text { [12] }\end{array}$ \\
\hline Triptolide & ABCA1 & Induce & $\uparrow L P S / T L R 4 / G P S 2$ & Natural & $\begin{array}{l}\text { Chen J } \\
\text { et al., } 2014 \text { [41] }\end{array}$ \\
\hline Cilostazol & $\mathrm{ABCA} 1$ & Induce & $\uparrow L X R / A B C A 1 / S R E B P-1$ & Synthetic & $\begin{array}{l}\text { Jeon BH } \\
\text { et al., } 2015 \text { [94] }\end{array}$ \\
\hline $\mathrm{H}_{2} \mathrm{~S}$ & $A B C A 1$ & Induce & $\uparrow P I 3-K / A k t / P P A R a$ & Synthetic & $\begin{array}{l}\text { Li D } \\
\text { et al., } 2016 \text { [95] }\end{array}$ \\
\hline Paeonol & $A B C A 1$ & Induce & $\downarrow$ Calpain-related pathway & Natural & $\begin{array}{l}\text { Li X } \\
\text { et al., } 2015 \text { [96] }\end{array}$ \\
\hline Dgn & $\mathrm{ABCA} 1$ & Induce & $\downarrow$ miR-19b expression & Natural & $\begin{array}{l}\text { LV YC } \\
\text { et al., } 2015 \text { [67] }\end{array}$ \\
\hline Hydrogen & $\mathrm{ABCA} 1$ & Induce & & Synthetic & $\begin{array}{l}\text { Song G } \\
\text { et al., } 2015 \text { [97] }\end{array}$ \\
\hline Metformin & $\mathrm{ABCG}$ \& ABCG8 & Induce & $\uparrow L d l r \uparrow A M P K \downarrow A C L Y$ & Synthetic & $\begin{array}{l}\text { Molusky MM } \\
\text { et al., } 2018 \text { [98] }\end{array}$ \\
\hline CoQ10 & ABCG1 & Induce & $\uparrow$ Activator protein-1/miR-378/ABCG1 & Natural & $\begin{array}{l}\text { Wang D } \\
\text { et al., } 2014 \text { [99] }\end{array}$ \\
\hline Progesterone & $\mathrm{ABCA} 2$ & Induce & $\uparrow m R N A$ expression & Synthetic\& Natural & $\begin{array}{l}\text { Davis W } \\
\text { et al., } 2018 \text { [47] }\end{array}$ \\
\hline
\end{tabular}

Abbreviations: $A B C$ adenosine triphosphate-binding cassette; PI3-K phosphatidylinositol 3-kinase; Akt protein kinase $\mathrm{B}$; FOXO1 forkhead box protein O1; TLR4 Tolllike receptor 4; LPS lipopolysaccharides; GPS2 G protein pathway suppressor 2; LXR liver X receptor; SREBP-1 sterol regulatory element binding protein 1; miR microRNA; $\mathrm{H}_{2} \mathrm{~S}$ hydrogen sulfide; PPARa peroxisome proliferator-activated receptor a; Dgn Diosgenin; Ldlr low density lipoprotein receptor; AMPK AMP-activated protein kinase; ACLY ATP citrate lyase; CoQ10 Coenzyme Q10 
mRNA expression and relevant signaling pathways to alter $\mathrm{ABC}$ transporters.

\section{Statins}

Stains have been reported to reduce ABCA1 expression. For example, atorvastatin can decrease Akt phosphorylation [12]. Thus, the PI3-K/Akt/FOXO1 pathway can be suppressed, which consequently suppresses the gene expression of $A B C A 1$. In addition, statins can also downregulate $A B C A 1$ mRNA by upregulating miR-33 levels. It is likely that miR-33 inhibits the TLR4/ NF- $\mathrm{kB}$ pathway to decrease the expression of ABCA1.

\section{Triptolide}

Triptolide can regulate $\mathrm{ABCA} 1$ gene and protein expression to promote the expression of ABCA1, reducing the secretion of inflammatory factors and alleviating the lung pathological injury associated with LPS-induced acute lung injury (ALI) [41]. Thus, triptolide may mediate the expression of ABCA1 through the LPS/TLR4/ GPS2 pathway to suppress inflammation.

\section{Cilostazol}

Cilostazol, a phosphodiesterase 3, has been widely used to treat arterial disease and has additional beneficial effects on dyslipidemia. Cilostazol can ameliorate hepatic steatosis by increasing ABCA1 expression in hepatocytes [94]. The possible signaling pathway may be the LXR/ ABCA1/SREBP-1 pathway in hepatocytes.

\section{Hydrogen sulfide}

Li D et al. [95] indicated that hydrogen sulfide $\left(\mathrm{H}_{2} \mathrm{~S}\right)$ had an antiatherosclerotic effect. NaHS (an exogenous $\mathrm{H}_{2} \mathrm{~S}$ donor) treatment significantly increased the expression of ABCA1, apoA-I, and apoA-II to ameliorate intracellular lipid accumulation in HepG2 cells. $\mathrm{H}_{2} \mathrm{~S}$ upregulates the expression of ABCA1 by promoting the nuclear translocation of PPAR $\alpha$, which is a transcription factor that regulates lipid metabolism [95]. The signaling pathway may be PI3-K/Akt/ PPAR $\alpha$.

\section{Paeonol}

Paeonol, a potent antioxidant isolated from cortex moutan, exerts atheroprotective effects. Paeonol upregulates the protein stability of ABCA1 by inhibiting calpain activity and consequently affecting calpain-related pathways. Paeonol slows AS by repressing foam cell formation through heme oxygenase-1 (Ho-1)-dependent mediation of cholesterol efflux in macrophages. Furthermore, paeonol can modulate the expression of CD36 and ABCA1 in aortas [96].

\section{Diosgenin}

Lv YC et al. [67] found that a structural analog of cholesterol, diosgenin (Dgn), could reduce blood fat levels and ameliorate atherosclerosis. Dgn enhanced ABCA1dependent cholesterol efflux and inhibited aortic AS progression by suppressing macrophage miR-19b expression [67].

\section{Hydrogen}

Hydrogen (dihydrogen $\left[\mathrm{H}_{2}\right]$ ) can suppress hypercholesterolemia and AS [97]. Specifically, $\mathrm{H}_{2}$ can decrease plasma LDL-C levels, activate ABCA1-dependent efflux and enhance $\mathrm{HDL}$ antiatherosclerotic functions in patients with potential MetS.

\section{Metformin}

Molusky MM et al. [98] reported that metformin might upregulate macrophage RCT. The final steps of RCT are mediated by the sterol transporters, ABCG5 and ABCG8, which facilitate hepatobiliary transport of cholesterol. Metformin can provide cardiovascular benefits by increasing RCT and possibly enhancing low-density lipoprotein receptor (Ldlr) expression. Ldlr can activate AMP-activated protein kinase (AMPK) and can inhibit ATP citrate lyase (ACLY) to induce an increase in $\mathrm{ABCG} / 8$, and ABCG5/8 can then facilitate the disposal of excess cholesterol by excretion into bile.

\section{Coenzyme Q10}

Coenzyme Q10 (CoQ10) can increase macrophage RCT by regulating miRNA expression. Activator protein-1/ miR-378/ABCG1 is a novel cascade by which CoQ10 facilitates macrophage cholesterol efflux. Both $\mathrm{CoQ} 10$ and miR-378 are promising candidates for AS prevention and treatment [99].

\section{Progesterone}

Progesterone mimics the cellular physiological effects of ABCA2 in cells and elevates ABCA2 mRNA expression. Consequently, progesterone can alleviate cholesterolinduced toxicity in macrophages by modulating cholesterol trafficking from the LE/LY to the ER [47].

\section{Conclusions}

Abnormal lipid metabolism commonly occurs in metabolic diseases, and $\mathrm{ABC}$ transporters have received increasing attention for their potential to treat several metabolic diseases simultaneously. $\mathrm{ABC}$ proteins can regulate lipid transport by an opening and closing transport cycle. In addition, the ability of $\mathrm{ABC}$ transporters to induce MDR and the promoting effect of metabolic diseases on cancer also highlight the significance of $A B C$ proteins in cancer with concomitant metabolic disease. 
In this review, we mainly focused on the relationship between $\mathrm{ABC}$ transporters and metabolic diseases. $\mathrm{ABC}$ transporters are able to improve cholesterol homeostasis by facilitating HDL-C assembly. Impairment of $A B C$ transporters can lead to a variety of metabolic diseases, such as obesity, AS, T2DM and TD. The ABC transporter family can influence various signaling pathways to mediate the internal environment. For example, the expression of ABCA1 can suppress SREBP, which can repress lipogenesis. In addition, $\mathrm{ABC}$ transporters can also be controlled by several transcription factors. For example, LXR can induce the expression of ABCA1. FOXO1 can upregulate ABCA1 and ABCG5/8 expression at the same time. Among $\mathrm{ABC}$ transporters, ABCA1 and ABCG1 have received the most attention regarding metabolic diseases. Since other $A B C$ transporters, such as ABCA2 have similar capabilities to control lipid transport, an extensive understanding of other family members might give us a broader scope to treat metabolic and related diseases. Moreover, MDR associated with $\mathrm{ABC}$ transporters in cancer has been intensively studied. However, MDR in metabolic diseases has not received much attention. We hope that further studies might focus on the influence of MDR on drugs to treat metabolic diseases to optimize $\mathrm{ABC}$ transporterbased therapy. In addition, it is important to clearly identify MDR-associated $\mathrm{ABC}$ transporter members to improve drug therapeutic effects.

ABC transporter-related miRNA therapy has been identified as a promising strategy to radically treat metabolic diseases. This therapy is expected to have a robust efficacy and excellent specificity. It is fundamental to have an overall understanding of the correlation with miRNAs and $A B C$ proteins. Currently, several drugs have been developed or are in development to treat metabolic diseases by regulating signaling pathways and mRNAs. Additionally, metabolic diseases can promote the development of cancer. Thus, it is essential to selectively regulate the expression of different $A B C$ transporters, especially in cancer patients with concomitant metabolic diseases.

\section{Abbreviations}

ATP: Adenosine triphosphate; ABC: Adenosine triphosphate-binding cassette; TMDs: Transmembrane domains; MDR: Multidrug resistance; BBB: Blood-brain barrier; HDL-C: HDL cholesterol; TC: Total cholesterol; LDL-C: Low-density lipoprotein-cholesterol; AS: Atherosclerosis; HA: Hypoalphalipoproteinemia; CAD: Coronary artery disease; TD: Tangier disease; NBDs: Cytoplasmic nucleotide-binding domains; FT: Full-transporter; HT: Half-transporter; TMDO: Additional TMD; SBPs: Substrate-binding proteins; RCT: Reverse cholesterol transportation; apo: Apolipoprotein; SR-BI: Scavenger receptor-Bl; T2DM: Type 2 diabetes mellitus; HLCs: Hepatocyte-like cells; TG: Triglyceride; LPS: Lipopolysaccharide; LXRs: Liver X receptors; RXR: Retinoid-X-receptor; PPARs: Peroxisome proliferator-activated receptors; NF-KB: Nuclear factor kappa-light-chain-enhancer of activated B cells; GPS2: G protein pathway suppressor 2; ARF6: ADP-ribosylation factor 6; IL-6: Interleukin 6; CRP: CReactive Protein; ER: Endoplasmic reticulum; RDS: Respiratory distress syndrome; NKT: Natural killer T; CYP450: Cytochrome P450; MRP1: Multidrug resistance protein 1; TGN: Trans-Golgi network; ERC: Endosomal recycling compartment; PP: Protoporphyria; EPP: Erythropoietic protoporphyria; BLI: Bioluminescence imagine; miRNAs: MicroRNAs; 30-UTR: 30-untranslated region; SNPs: Single nucleotide polymorphisms; AIS: Acute ischemic stroke; MAP K1: Mitogen-activated protein kinase 1; LPP: Lipoma-preferred partner; TLR: Toll-like receptor; NAFLD: Non-alcoholic fatty liver disease;

UPR: Unfolded protein response; MetS: Metabolic syndrome; oxLDL: Oxidized

LDL; VLDL: Very-low-density lipoprotein; LE/LY: Late-endosome/ lysosomal membrane compartment; CRH: Corticotropin-releasing hormone;

CRHR1: Corticotropin-releasing hormone receptor 1; Akt: Protein kinase B; PI3-K: Phosphatidylinositol 3-kinase; PAPP-A: Pregnancy-associated plasma protein-A; WM: White matter; IGF-1: Insulin-like growth factor 1; FoxO1: Forkhead box protein 01; GLP-1: Glucagon-like peptide-1; OSBP: Oxysterol binding protein; EPC: Endothelial progenitor cell; CHD: Coronary heart disease; ANGPTL3: Angiopoietin related protein 3; LPL: Lipoprotein lipase; TXA2: Thromboxane A2; ALl: Acute lung injury; $\mathrm{H}_{2} \mathrm{~S}$ : Hydrogen sulfide; Ho-1: Heme oxygenase-1; Dgn: Diosgenin "i Ldlr: Lipoprotein receptor; AMPK: AMP-activated protein kinase; SREBP2: sterol regulatory element binding protein 2

\section{Acknowledgments}

Not applicable.

\section{Authors' contributions}

T.W. contributed to design the research and review of the final version of the manuscript. Z.X.Y contributed to conduct/data collection, analysis of the research data and wrote the manuscript. Y.F.L. contributed to data collection. All authors contributed to and approved the final manuscript.

\section{Authors' information}

Center of Chinese Medical Therapy and Systems Biology, Institute of Interdisciplinary Integrative Medicine Research, Shanghai University of Traditional Chinese Medicine, Shanghai 201203, China.

\section{Funding}

This work was supported by the National Natural Science Foundation of China (81873076), the Shanghai Talents Development Fund Project in China (2017090) and the Innovation Project for Undergraduates of Shanghai University of Traditional Chinese Medicine (2019SHUTCM187).

Availability of data and materials

Not applicable.

Ethics approval and consent to participate

Not applicable.

Consent for publication

Not applicable.

\section{Competing interests}

The authors declare that they have no conflict of interest.

Received: 9 January 2020 Accepted: 22 July 2020

Published online: 03 August 2020

\section{References}

1. Gu RX, Corradi V, Singh G, Choudhury HG, Beis K, Tieleman DP. Conformational changes of the antibacterial peptide ATP binding cassette transporter McjD revealed by molecular dynamics simulations. Biochemistry. 2015;54:5989-98.

2. Taylor NMI, Manolaridis I, Jackson SM, Kowal J, Stahlberg H, Locher KP. Structure of the human multidrug transporter ABCG2. Nature. 2017;546: 504-9.

3. Xiong J, Feng J, Yuan D, Zhou J, Miao W. Tracing the structural evolution of eukaryotic ATP binding cassette transporter superfamily. Sci Rep. 2015;5: 16724.

4. Iram SH, Gruber SJ, Raguimova ON, Thomas DD, Robia SL. ATP-binding cassette transporter structure changes detected by Intramolecular fluorescence energy transfer for high-throughput screening. Mol Pharmacol. 2015;88:84-94. 
5. Harris MT, Hussain SS, Inouye CM, Castle AM, Castle JD. Reinterpretation of the localization of the ATP binding cassette transporter ABCG1 in insulinsecreting cells and insights regarding its trafficking and function. PLoS One. 2018;13:e0198383.

6. Saha J, Sengupta A, Gupta K, Gupta B. Molecular phylogenetic study and expression analysis of ATP-binding cassette transporter gene family in Oryza sativa in response to salt stress. Comput Biol Chem. 2015;54:18-32.

7. Clifton MC, Simon MJ, Erramilli SK, Zhang H, Zaitseva J, Hermodson MA, et al. In vitro reassembly of the ribose ATP-binding cassette transporter reveals a distinct set of transport complexes. J Biol Chem. 2015;290:5555-65.

8. Bi Y, Mann E, Whitfield C, Zimmer J. Architecture of a channel-forming Oantigen polysaccharide ABC transporter. Nature. 2018;553:361-5.

9. Qian H, Zhao X, Cao P, Lei J, Yan N, Gong X. Structure of the human lipid exporter ABCA1. Cell. 2017;169:1228-39 e10.

10. Liu H, Cheng M, Zhao S, Lin C, Song J, Yang Q. ATP-Binding Cassette Transporter Regulates N,N'-diacetylchitobiose Transportation and Chitinase Production in Trichoderma asperellum T4. Int J Mol Sci. 2019;20:2412.

11. Laub KR, Marek M, Stanchev LD, Herrera SA, Kanashova T, Bourmaud A, et al. Purification and characterisation of the yeast plasma membrane ATP binding cassette transporter Pdr11p. PLoS One. 2017;12:e0184236.

12. Chen WM, Sheu WH, Tseng PC, Lee TS, Lee WJ, Chang PJ, et al. Modulation of microRNA expression in subjects with metabolic syndrome and decrease of cholesterol efflux from macrophages via microRNA-33-mediated attenuation of ATP-binding cassette transporter A1 expression by statins. PLoS One. 2016:11:e0154672.

13. Babashamsi MM, Halalkhor S, Moradi Firouzjah H, Parsian H, Jalali SF, Babashamsi M. Association of ATP-binding cassette transporter A1 (ABCA1)$565 \mathrm{C} / \mathrm{T}$ gene polymorphism with Hypoalphalipoproteinemia and serum lipids, IL-6 and CRP levels. Avicenna J Med Biotechnol. 2016;9:38-43.

14. Liu L, Zhang M, Min X, Cai L. Low serum levels of ABCA1, an ATP-binding cassette transporter, are predictive of preeclampsia. Tohoku J Exp Med. 2015;236:89-95

15. Lara FA, Pohl PC, Gandara AC, Ferreira Jda S, Nascimento-Silva MC, Bechara $\mathrm{GH}$, et al. ATP binding cassette transporter mediates both Heme and pesticide detoxification in tick Midgut cells. PLoS One. 2015;10:e0134779.

16. Lu H, Xu Y, Cui F. Phylogenetic analysis of the ATP-binding cassette transporter family in three mosquito species. Pestic Biochem Physiol. 2016;132:118-24.

17. Chen Y, Zhang L, Liu W, Wang K. Case-control study of metabolic syndrome and ovarian cancer in Chinese population. Nutr Metab (Lond). 2017;14:21.

18. Xiong $T$, Xu G, Huang $X L$, Lu KQ, Xie WQ, Yin $K$, et al. ATP-binding cassette transporter A1: a promising therapy target for prostate cancer. Mol Clin Oncol. 2018;8:9-14.

19. Malvi P, Chaube B, Singh SV, Mohammad N, Pandey V, Vijayakumar MV, et al. Weight control interventions improve therapeutic efficacy of dacarbazine in melanoma by reversing obesity-induced drug resistance. Cancer Metab. 2016:4:21.

20. Malvi P, Chaube B, Pandey V, Vijayakumar MV, Boreddy PR, Mohammad N, et al. Obesity induced rapid melanoma progression is reversed by orlistat treatment and dietary intervention: role of adipokines. Mol Oncol. 2015;9: 689-703.

21. Malvi P, Chaube B, Singh SV, Mohammad N, Vijayakumar MV, Singh S, et al. Elevated circulatory levels of leptin and resistin impair therapeutic efficacy of dacarbazine in melanoma under obese state. Cancer Metab. 2018;6:2.

22. Raposeiras Roubin S, Cordero A. The Two-way Relationship Between Cancer and Atherosclerosis. Rev Esp Cardiol (Engl Ed). 2019;72:487-94.

23. Balzan S, Lubrano V. LOX-1 receptor: a potential link in atherosclerosis and cancer. Life Sci. 2018;198:79-86.

24. Bera K, Rani P, Kishor G, Agarwal S, Kumar A, Singh DV. Structural elucidation of transmembrane domain zero (TMD0) of EcdL: a multidrug resistance-associated protein (MRP) family of ATP-binding cassette transporter protein revealed by atomistic simulation. J Biomol Struct Dyn. 2018;36:2938-50.

25. Yu HZ, Xu JP, Wang XY, Ma Y, Yu D, Fei DQ, et al. Identification of four ATPbinding cassette transporter genes in Cnaphalocrocis medinalis and their expression in response to insecticide treatment. J Insect Sci. 2017;17:44.

26. Sakamoto M, Suzuki H, Yura K. Relationship between conformation shift and disease related variation sites in ATP-binding cassette transporter proteins. Biophys Physicobiol. 2019;16:68-79.

27. Miglionico R, Gerbino A, Ostuni A, Armentano MF, Monne M, Carmosino M, et al. New insights into the roles of the N-terminal region of the ABCC6 transporter. J Bioenerg Biomembr. 2016;48:259-67.
28. Ho H, Miu A, Alexander MK, Garcia NK, Oh A, Zilberleyb I, et al. Structural basis for dual-mode inhibition of the ABC transporter MsbA. Nature. 2018; 557:196-201.

29. Kim J, Wu S, Tomasiak TM, Mergel C, Winter MB, Stiller SB, et al. Subnanometre-resolution electron cryomicroscopy structure of a heterodimeric ABC exporter. Nature. 2015;517:396-400.

30. Xie XL, Li CH, Yang YX, Jin L, Tan JJ, Zhang XY, et al. Allosteric transitions of ATP-binding cassette transporter MsbA studied by the adaptive anisotropic network model. Proteins. 2015;83:1643-53.

31. Hofmann S, Januliene D, Mehdipour AR, Thomas C, Stefan E, Bruchert S, et al. Conformation space of a heterodimeric $A B C$ exporter under turnover conditions. Nature. 2019;571:580-3.

32. Weng J, Gu S, Gao X, Huang X, Wang W. Maltose-binding protein effectively stabilizes the partially closed conformation of the ATP-binding cassette transporter MalFGK2. Phys Chem Chem Phys. 2017;19:9366-73.

33. Castella B, Kopecka J, Sciancalepore P, Mandili G, Foglietta M, Mitro N, et al. The ATP-binding cassette transporter A1 regulates phosphoantigen release and Vgamma9Vdelta2 T cell activation by dendritic cells. Nat Commun. 2017;8:15663.

34. Mukhamedova N, Hoang A, Cui HL, Carmichael I, Fu Y, Bukrinsky M, et al. Small GTPase ARF6 regulates Endocytic pathway leading to degradation of ATP binding cassette transporter A1. Arterioscler Thromb Vasc Biol. 2016;36: 2292-303.

35. Hasan MM, Hosen MB, Rahman MM, Howlader MZH, Kabir Y. Association of ATP binding cassette transporter 1 (ABCA 1) gene polymorphism with type 2 diabetes mellitus (T2DM) in Bangladeshi population. Gene. 2019;688:151-4.

36. Ghaznavi H, Aali E, Soltanpour MS. Association study of the ATP - binding cassette transporter A1 (ABCA1) Rs2230806 genetic variation with lipid profile and coronary artery disease risk in an Iranian population. Open Access Maced J Med Sci. 2018;6:274-9.

37. Bi X, Pashos EE, Cuchel M, Lyssenko NN, Hernandez M, Picataggi A, et al. ATP-binding cassette transporter A1 deficiency in human induced pluripotent stem cell-derived hepatocytes abrogates HDL biogenesis and enhances triglyceride secretion. EBioMedicine. 2017;18:139-45.

38. Vincent V, Thakkar H, Aggarwal S, Mridha AR, Ramakrishnan L, Singh A. ATPbinding cassette transporter A1 (ABCA1) expression in adipose tissue and its modulation with insulin resistance in obesity. Diabetes Metab Syndr Obes. 2019:12:275-84.

39. Fawzy MS, Alhadramy O, Hussein MH, Ismail HM, Ismail NM, Biomy NM, et al. Functional and structural impact of ATP-binding cassette transporter A1 R219K and 1883M gene polymorphisms in obese children and adolescents. Mol Diagn Ther. 2015;19:221-34.

40. Huang Z, Liang N, Damdimopoulos A, Fan R, Treuter E. G protein pathway suppressor 2 (GPS2) links inflammation and cholesterol efflux by controlling lipopolysaccharide-induced ATP-binding cassette transporter A1 expression in macrophages. FASEB J. 2019;33:1631-43.

41. Chen J, Gao J, Yang J, Zhang Y, Wang L. Effect of triptolide on the regulation of ATPbinding cassette transporter $\mathrm{A} 1$ expression in lipopolysaccharideinduced acute lung injury of rats. Mol Med Rep. 2014;10: 3015-20.

42. Haghvirdizadeh P, Ramachandran V, Etemad A, Heidari F, Ghodsian N, Bin Ismail $\mathrm{N}$, et al. Association of ATP-binding cassette transporter A1 gene polymorphisms in type 2 diabetes mellitus among Malaysians. J Diabetes Res. 2015;2015:289846.

43. Kolovou V, Marvaki A, Boutsikou M, Vasilopoulos G, Degiannis D, Marvaki C, et al. Effect of ATP-binding cassette transporter A1 (ABCA1) gene polymorphisms on plasma lipid variables and common demographic parameters in Greek nurses. Open Cardiovasc Med J. 2016;10:233-9.

44. Huwait EA, Singh NN, Michael DR, Davies TS, Moss JW, Ramji DP. Protein kinase $C$ is involved in the induction of ATP-binding cassette transporter A1 expression by liver $X$ receptor/retinoid $X$ receptor agonist in human macrophages. J Cell Biochem. 2015;116:2032-8.

45. Lu R, Zheng Z, Yin Y, Jiang Z. Effect of Genistein on cholesterol metabolismrelated genes in HepG2 cell. J Food Sci. 2019;84:2330-6.

46. Cho W, Kang JL, Park YM. Corticotropin-releasing hormone (CRH) promotes macrophage foam cell formation via reduced expression of ATP binding cassette Transporter-1 (ABCA1). PLoS One. 2015;10:e0130587.

47. Davis W Jr, Tew KD. ATP-binding cassette transporter-2 (ABCA2) as a therapeutic target. Biochem Pharmacol. 2018;151:188-200.

48. Wambach JA, Yang P, Wegner DJ, Heins HB, Kaliberova LN, Kaliberov SA, et al. Functional characterization of ATP-binding cassette transporter A3 
mutations from infants with respiratory distress syndrome. Am J Respir Cell Mol Biol. 2016;55:716-21.

49. Rezaei F, Shafiei M, Shariati G, Dehdashtian A, Mohebbi M, Galehdari H. Novel mutation in the ATP-binding cassette transporter A3 (ABCA3) encoding gene causes respiratory distress syndrome in a term newborn in Southwest Iran. Iran J Pediatr. 2016;26:e2493.

50. Tanaka N, Abe-Dohmae S, Iwamoto N, Yokoyama S. Roles of ATP-binding cassette transporter A7 in cholesterol homeostasis and host defense system. J Atheroscler Thromb. 2011;18:274-81.

51. Nowyhed HN, Chandra S, Kiosses W, Marcovecchio P, Andary F, Zhao M, et al. ATP binding cassette transporter ABCA7 regulates NKT cell development and function by controlling CD1d expression and lipid raft content. Sci Rep. 2017;7:40273.

52. Aikawa $T$, Ren $Y$, Yamazaki $Y$, Tachibana M, Johnson MR, Anderson $C T$, et al. ABCA7 haplodeficiency disturbs microglial immune responses in the mouse brain. Proc Natl Acad Sci U S A. 2019;116:23790-6.

53. Sasaki $K$, Tachikawa M, Uchida $Y$, Hirano S, Kadowaki F, Watanabe M, et al. ATP-binding cassette transporter a subfamily 8 is a sinusoidal efflux transporter for cholesterol and Taurocholate in mouse and human liver. Mol Pharm. 2018;15:343-55.

54. Chavan H, Li F, Tessman R, Mickey K, Dorko K, Schmitt T, et al. Functional coupling of ATP-binding cassette transporter Abcb6 to cytochrome P450 expression and activity in liver. J Biol Chem. 2015;290:7871-86.

55. Johnson ZL, Chen J. ATP binding enables substrate release from multidrug resistance protein 1. Cell. 2018;172:81-9 e10

56. Pandzic E, Gelissen IC, Whan R, Barter PJ, Sviridov D, Gaus K, et al. The ATP binding cassette transporter, ABCG1, localizes to cortical actin filaments. Sci Rep. 2017:7:42025.

57. Gu HM, Wang F, Alabi A, Deng S, Qin S, Zhang DW. Identification of an amino acid residue critical for plasma membrane localization of ATPbinding cassette transporter G1--brief report. Arterioscler Thromb Vasc Biol. 2016:36:253-5

58. Li Q, Liu X, Zhu R, He Z. Association of ATP-binding cassette transporter G1 polymorphisms with risk of ischemic stroke in the Chinese Han population. J Stroke Cerebrovasc Dis. 2015;24:1397-404.

59. Hoekstra M, Ouweneel AB, Nahon JE, van der Geest R, Kroner MJ, van der Sluis RJ, et al. ATP-binding cassette transporter G1 deficiency is associated with mild glucocorticoid insufficiency in mice. Biochim Biophys Acta Mol Cell Biol Lipids. 1864;2019:443-51

60. Wang Y, Lin Z, Zhang B, Nie A, Bian M. Cichorium intybus L. promotes intestinal uric acid excretion by modulating $A B C G 2$ in experimental hyperuricemia. Nutr Metab. 2017;14:38.

61. Hagiwara S, Nishida N, Park AM, Sakurai T, Kawada A, Kudo M. Impaired expression of ATP-binding cassette transporter G2 and liver damage in erythropoietic protoporphyria. Hepatology. 2015;62:1638-9.

62. Bakhsheshian J, Wei BR, Hall MD, Simpson RM, Gottesman MM. In vivo bioluminescent imaging of ATP-binding cassette transporter-mediated efflux at the blood-brain barrier. Methods Mol Biol. 2016;1461:227-39.

63. Tiwari A, Mukherjee B, Dixit M. MicroRNA Key to angiogenesis regulation: MiRNA biology and therapy. Curr Cancer Drug Targets. 2018;18:266-77.

64. Hosseinahli N, Aghapour M, Duijf PHG, Baradaran B. Treating cancer with microRNA replacement therapy: a literature review. J Cell Physiol. 2018;233:5574-88.

65. Rupaimoole R, Slack FJ. MicroRNA therapeutics: towards a new era for the management of cancer and other diseases. Nat Rev Drug Discov. 2017;16: 203-22.

66. O'Brien J, Hayder H, Zayed Y, Peng C. Overview of MicroRNA Biogenesis, Mechanisms of Actions, and Circulation. Front Endocrinol. 2018:9:402.

67. Lv YC, Yang J, Yao F, Xie W, Tang YY, Ouyang XP, et al. Diosgenin inhibits atherosclerosis via suppressing the MiR-19b-induced downregulation of ATP-binding cassette transporter A1. Atherosclerosis. 2015;240:80-9.

68. Liang B, Wang X, Song X, Bai R, Yang H, Yang Z, et al. MicroRNA-20a/b regulates cholesterol efflux through post-transcriptional repression of ATPbinding cassette transporter A1. Biochim Biophys Acta Mol Cell Biol Lipids. 1862;2017:929-38

69. Yang S, Ye ZM, Chen S, Luo XY, Chen SL, Mao L, et al. MicroRNA-23a-5p promotes atherosclerotic plaque progression and vulnerability by repressing ATP-binding cassette transporter A1/G1 in macrophages. J Mol Cell Cardiol. 2018;123:139-49.

70. Liu J, Liu XQ, Liu Y, Sun YN, Li S, Li CM, et al. MicroRNA 28-5p regulates ATP-binding cassette transporter A1 via inhibiting extracellular signalregulated kinase 2. Mol Med Rep. 2016;13:433-40.
71. Niesor EJ, Schwartz GG, Perez A, Stauffer A, Durrwell A, Bucklar-Suchankova $\mathrm{G}$, et al. Statin-induced decrease in ATP-binding cassette transporter A1 expression via microRNA33 induction may counteract cholesterol efflux to high-density lipoprotein. Cardiovasc Drugs Ther. 2015;29:7-14.

72. Lai L, Azzam KM, Lin WC, Rai P, Lowe JM, Gabor KA, et al. MicroRNA-33 regulates the innate immune response via ATP binding cassette transportermediated remodeling of membrane microdomains. J Biol Chem. 2016;291: 19651-60.

73. Zhang N, Lei J, Lei H, Ruan X, Liu Q, Chen Y, et al. MicroRNA-101 overexpression by IL-6 and TNF-alpha inhibits cholesterol efflux by suppressing ATP-binding cassette transporter A1 expression. Exp Cell Res. 2015;336:33-42.

74. Yao Y, Li Q, Wang W, Zhang J, Gao P, Xu Y. Glucagon-like Peptide-1 modulates cholesterol homeostasis by suppressing the miR-19b-induced Downregulation of ABCA1. Cell Physiol Biochem. 2018;50:679-93.

75. Cuffe H, Liu M, Key CC, Boudyguina E, Sawyer JK, Weckerle A, et al. Targeted deletion of adipocyte Abca1 (ATP-binding cassette transporter A1) impairs diet-induced obesity. Arterioscler Thromb Vasc Biol. 2018;38:733-43.

76. Chistiakov DA, Melnichenko AA, Myasoedova VA, Grechko AV, Orekhov AN. Mechanisms of foam cell formation in atherosclerosis. J Mol Med (Berl). 2017;95:1153-65.

77. Yin YW, Wang Q, Sun QQ, Hu AM, Liu HL. ATP-binding cassette transporter 1 C69T and V825I polymorphisms in the development of atherosclerosis: a meta-analysis of 18,320 subjects. Thromb Res. 2015;135:130-6.

78. Takiguchi S, Ayaori M, Yakushiji E, Nishida T, Nakaya K, Sasaki M, et al. Hepatic overexpression of endothelial lipase lowers high-density lipoprotein but maintains reverse cholesterol transport in mice: role of scavenger receptor class B type I/ATP-binding cassette transporter A1-dependent pathways. Arterioscler Thromb Vasc Biol. 2018;38:1454-67.

79. Bi X, Zhu X, Gao C, Shewale S, Cao Q, Liu M, et al. Myeloid cell-specific ATPbinding cassette transporter $\mathrm{A} 1$ deletion has minimal impact on atherogenesis in atherogenic diet-fed low-density lipoprotein receptor knockout mice. Arterioscler Thromb Vasc Biol. 2014:34:1888-99.

80. LV Y, Yang J, Gao A, Sun S, Zheng X, Chen X, et al. Sortilin promotes macrophage cholesterol accumulation and aortic atherosclerosis through lysosomal degradation of ATP-binding cassette transporter A1 protein. Acta Biochim Biophys Sin Shanghai. 2019;51:471-83.

81. Mokuno J, Hishida A, Morita E, Sasakabe T, Hattori Y, Suma S, et al. ATPbinding cassette transporter A1 (ABCA1) R219K (G1051A, rs2230806) polymorphism and serum highdensity lipoprotein cholesterol levels in a large Japanese population: cross-sectional data from the Daiko study. Endocr J. 2015:62:543-9.

82. Mahmoodi K, Kamali K, Ghaznavi H, Soltanpour MS. The C-565T polymorphism (rs2422493) of the ATP-binding cassette transporter A1 gene contributes to the development and severity of coronary artery disease in an Iranian population. Oman Med J. 2018:33:309-15.

83. Cui X, Chopp M, Zacharek A, Karasinska JM, Cui Y, Ning R, et al. Deficiency of brain ATP-binding cassette transporter A-1 exacerbates blood-brain barrier and white matter damage after stroke. Stroke. 2015;46:827-34.

84. Dong T, Lyu J, Imachi H, Kobayashi T, Fukunaga K, Sato S, et al. Selective peroxisome proliferator-activated receptor-alpha modulator K-877 regulates the expression of ATP-binding cassette transporter A1 in pancreatic beta cells. Eur J Pharmacol. 2018;838:78-84.

85. Jung D, Cao S, Liu M, Park S. A meta-analysis of the associations between the ATP-binding cassette transporter ABCA1 R219K (rs2230806) polymorphism and the risk of type 2 diabetes in Asians. Horm Metab Res. 2018;50:308-16.

86. Lyu J, Imachi H, Iwama H, Zhang H, Murao K. Insulin-like growth factor 1 regulates the expression of ATP-binding cassette transporter $A 1$ in pancreatic Beta cells. Horm Metab Res. 2016:48:338-44.

87. Yao Y, Xu Y, Wang W, Zhang J, Li Q. Glucagon-like peptide-1 improves betacell dysfunction by suppressing the miR-27a-induced downregulation of ATPbinding cassette transporter A1. Biomed Pharmacother. 2017;96:497-502.

88. Shi Y, LV X, Liu Y, Li B, Liu M, Yan M, et al. Elevating ATP-binding cassette transporter $\mathrm{G} 1$ improves re-endothelialization function of endothelial progenitor cells via Lyn/Akt/eNOS in diabetic mice. FASEB J. 2018;32:6525-36.

89. Lu Y, Liu Y, Li Y, Zhang H, Yu M, Kanu JS, et al. Association of ATP-binding cassette transporter A1 gene polymorphisms with plasma lipid variability and coronary heart disease risk. Int J Clin Exp Pathol. 2015;8:13441-9.

90. Lhermusier T, Severin S, Van Rothem J, Garcia C, Bertrand-Michel J, Le Faouder $P$, et al. ATP-binding cassette transporter 1 (ABCA1) deficiency decreases platelet reactivity and reduces thromboxane $A 2$ production independently of hematopoietic ABCA1. J Thromb Haemost. 2016;14:585-95. 
91. Cui H, Zhang A, Chen M, Liu J. ABC transporter inhibitors in reversing multidrug resistance to chemotherapy. Curr Drug Targets. 2015;16:1356-71.

92. Mohammad IS, He W, Yin L. Understanding of human ATP binding cassette superfamily and novel multidrug resistance modulators to overcome MDR. Biomed Pharmacother. 2018;100:335-48.

93. Bhagya N, Chandrashekar KR. Tetrandrine and cancer - An overview on the molecular approach. Biomed Pharmacother. 2018;97:624-32.

94. Jeon BH, Lee YH, Yun MR, Kim SH, Lee BW, Kang ES, et al. Increased expression of ATP-binding cassette transporter A1 (ABCA1) as a possible mechanism for the protective effect of cilostazol against hepatic steatosis. Metabolism. 2015;64:1444-53.

95. Li D, Xiong Q, Peng J, Hu B, Li W, Zhu Y, et al. Hydrogen sulfide upregulates the expression of ATP-binding cassette transporter A1 via promoting nuclear translocation of PPARalpha. Int J Mol Sci. 2016;17:635.

96. Li X, Zhou Y, Yu C, Yang H, Zhang C, Ye Y, et al. Paeonol suppresses lipid accumulation in macrophages via upregulation of the ATP-binding cassette transporter A1 and downregulation of the cluster of differentiation 36. Int J Oncol. 2015;46:764-74.

97. Song $G$, Lin $Q$, Zhao $H$, Liu M, Ye F, Sun Y, et al. Hydrogen activates ATPbinding cassette transporter A1-dependent efflux ex vivo and improves high-density lipoprotein function in patients with hypercholesterolemia: a double-blinded, randomized, and placebo-controlled trial. J Clin Endocrinol Metab. 2015;100:2724-33.

98. Molusky MM, Hsieh J, Lee SX, Ramakrishnan R, Tascau L, Haeusler RA, et al. Metformin and AMP kinase activation increase expression of the sterol transporters ABCG5/8 (ATP-binding cassette transporter G5/G8) with potential Antiatherogenic consequences. Arterioscler Thromb Vasc Biol. 2018:38:1493-503.

99. Wang D, Yan X, Xia M, Yang Y, Li D, Li X, et al. Coenzyme Q10 promotes macrophage cholesterol efflux by regulation of the activator protein-1/miR378/ATP-binding cassette transporter G1-signaling pathway. Arterioscler Thromb Vasc Biol. 2014;34:1860-70.

\section{Publisher's Note}

Springer Nature remains neutral with regard to jurisdictional claims in published maps and institutional affiliations.

Ready to submit your research? Choose BMC and benefit from:

- fast, convenient online submission

- thorough peer review by experienced researchers in your field

- rapid publication on acceptance

- support for research data, including large and complex data types

- gold Open Access which fosters wider collaboration and increased citations

- maximum visibility for your research: over $100 \mathrm{M}$ website views per year

At $\mathrm{BMC}$, research is always in progress.

Learn more biomedcentral.com/submissions 